Simon, S.M., and Varghese K. (2018). "Assessment of Organizational Culture in Construction - A case study approach." In: Proc. $26^{\text {th }}$ Annual Conference of the International. Group for Lean Construction (IGLC), González, V.A. (ed.), Chennai, India, pp. 348-357. DOI: doi.org/10.24928/2018/0396. Available at: www.iglc.net.

\title{
ASSESSMENT OF ORGANIZATIONAL CULTURE IN CONSTRUCTION -A CASE STUDY APPROACH
}

\author{
S. Manna Simon', and Koshy Varghese ${ }^{2}$
}

\begin{abstract}
Recent studies suggest that Lean concepts can be successfully adopted only when it is aligned with the organizational culture (OC). OC can be defined as the shared values and beliefs of people, according to which they perceive, react and act in any situation. For sustained and effective adoption of Lean, it is important to institute Lean philosophy in the core culture of an organization. To enable effective adoption, it is important to analyze and understand the organizational culture and its dimensions before inducing a change management strategy for sustaining Lean. The objective of this study is to understand the impact of prominent cultural dimensions on the different management levels of employees.

The paper presents, results and discussion of an exploratory study conducted using a case study approach. A construction company based in a metropolitan city in India was chosen based on its active program in Lean implementation. To analyze the cultural dimensions of the organization, Competing Values Framework (CVF) was chosen. The key dimensions based on which CVF assess the OC are dominant characteristics, management of employees, organizational leadership, organizational glue, criteria for success and strategic emphases. The data was collected through "Organizational Culture Assessment Instrument (OCAI)" and the target respondents were the top-management and middle-management staff. The data was analyzed by standard scoring mechanisms, to arrive at the particular type of organizational culture. Apart from the questionnaires, views, and opinions from the experts were also taken.

From the study, it was found that the perception of employees about the organizational culture varies with different management levels, which might be a potential threat to sustain Lean philosophy. The study concludes by emphasizing the need for detailed understanding on the impacts of cultural dimensions in an organization.
\end{abstract}

1 Doctoral Research Scholar, Building Technology \& Construction Management Division, Department of Civil Engineering, Indian Institute of TechnologyMadras, Chennai, Tamil Nadu, India.mannasimon92@gmail.com

2 Professor, Building Technology \& Construction Management Division, Department of Civil Engineering, Indian Institute of Technology Madras, Chennai, Tamil Nadu, India. koshy@iitm.ac.in 


\section{KEYWORDS}

Change Management, Commitment, Lean Construction, Lean Culture, Organizational Culture.

\section{INTRODUCTION}

After the publication of the book "The Machine that Changed the World" in the 1990's, the adoption of Lean practices, that was once confined to the automobile industry expanded to other service sectors.(Matthias Holweg 2007). Many organizations around the globe started to pilot Lean concepts in their projects. However, in the long run, most of these organizations were not able to sustain Lean concepts, as most of them tried to imitate Lean tools and techniques rather than understanding that Lean is a culture-based concept.

Lean concepts have percolated to the construction industry as "Lean Construction". Many large-scale organizations and SME's have tried adopting Lean Construction and has succeeded to some extent. Coming to the Indian context, Lean Construction has picked up in the recent years. Many large companies have tried and adopted Lean Construction. However, in the long run, these organizations are not able to sustain Lean Construction due to many reasons like hierarchical mind-set, cultural issues, lack of top management support, lack of discipline, lack of inclusiveness etc. as mentioned in the literature (Cano et al. 2015; Devaki and Jayanthi 2014; R. Jadhav et al. 2014). One of the key reason mentioned in the literature is "Culture". It can be seen that there is no alignment between the organizational culture and Lean culture. It is therefore important to align these cultures for sustaining Lean.

However, when we see the current state of the construction industry, aligning Organizational culture with Lean culture seems to be a challenge due to the inherent culture of the sector. In addition to the uniqueness of construction projects, unskilled and changing workforce, mindsets of the construction community and organizational structure disables the effective adoption of Lean construction. In this scenario, it is very important to understand the organizational culture of the construction sector and mold it in such a way that Lean construction can sustain and yield long-term benefits.

The overall objective of this paper is to assess the organizational culture and understand the impact of cultural parameters in enabling Lean.

\section{LITERATURE REVIEW}

The literature review has been structured in three parts. The first part gives a brief introduction to the organizational culture and different models for its assessment. The second part briefly reviews Lean culture. The third part throws light on the existing literature on organizational culture and Lean implementation and ends by identifying the gaps in the existing literature.

\section{ORGANIZATIONAL CULTURE}

The term organizational culture has been defined in many ways by different management scholars. One of the widely accepted definitions of organizational culture is given by 
Edgar Schein. He defines Organizational culture as "a pattern of shared basic assumptions that the group has invented, discovered, or developed in learning to cope with its problem of external adaptation and internal integration and that have worked well enough to be considered valid, and therefore, to be taught to new members as the correct way to perceive, think and feel in relation to those problems". In simple terms, organizational culture can be defined as the sharedbeliefs of a group of people, according to which they perceive, act and react. Researchers have tried to classify organizational culture through different methods and models. Some of the widely known models and methods are described below:

- Hofstede dimensions of culture: Hofstede states that an organizational culture and behavior is being influenced by the national and regional culture. He identified six dimensions of national culture which affects organizationalbehavior. Those six dimensions are: Power distance (extent to which less powerful members of an organization believe and accept that power is distributed unequally), Uncertainty avoidance (extent to which members can accept or avert uncertainties), Individualism vs. collectivism (integration of members into groups), Masculinity vs. femininity (extent to which members seek heroism, assertiveness or material reward instead of cooperation and quality of life), Long term vs. short term orientation (determines focus) and Indulgence vs. Restraint (it is generally the measure of happiness/gratification of getting basic needs and desires fulfilled) (Hofstede 2011; Zamanabadi 2017).

- Daniel Denison Model: Denison states that four dimension describes organizational culture. Those four dimensions are Mission, Adaptability, Involvement, and Consistency. Missionincludes strategic direction, objectives, vision, and goals. Adaptability focuses on the customer, organizational learning, and creating a change. Involvement includes employee empowerment, skill building, and team orientation. Consistency deals with the core values, coordination, and integration. (Denison and Neale 1999)

- Edgar Schein Model: Schein views an organizational culture as an observer and classifies it into three: Artifacts, espoused values, and basic underlying assumptions. Artifacts comprise of the visible part an organization that can be seen at the surface level of an organization like mission statements, slogans, dress codes, rituals etc. Espoused values define the core values embedded in the organizational member like norms. Basic underlying assumptions comprises of elements that are not visible, nor spoken. These values exist within the organizational members unconsciously and are taken-for-granted. (Schein 2004)

- Kim Cameron and Robert Quinn Model: Cameron and Quinn have proposed a framework which determines the organizational culture based on the flexibility, stability, external and internal focus of an organization. This model assesses the characteristics of an organization and distinguishes it into predefined cultural 
groups: Clan, Market Adhocracy, andHierarchical culture. (Cameron and Quinn 2006)

Apart from the mentioned models, there are several other models available such as Gerry Johnson's model, Stanley G. Harris model, Charles Handy model etc., that assess and classifies organizational culture. However, the central focus of this study remains on strategy, dominant characteristics, organizational glue, management of employees, leadership style and criteria for success.

\section{LEAN CULTURE}

Lean can be defined as a management philosophy of continuous improvement which consists of a set of practices and processes. For effective adoption of Lean philosophy in an organization, it is very important to understand what is "Lean Culture". Liker in his book titled "Toyota Culture" says that every Toyota plant has its own unique culture, based on its locality, leadership, history, and people. However, Toyota has developed certain core principles that have to be followed by every Toyota plant regardless of the location. Toyota actually established its philosophy (Kaizen and respect for people) as the foundation and built its core principle and strategy on it. Moreover, Toyota had methods and tools to enable their principles and strategy in addition to the performance measurement and control systems. It is important to understand that Toyota is able to sustain its practices because the whole "Toyota Way" is established on its philosophy. Liker in his book "The Toyota Way" describes 14 management principles based on the 4P model: Philosophy, Process, People \& Partners, and Problem solving. The 4P model emphasizes on adopting a long-term philosophy, process optimization, investing in people \& partners and seeking consensus with the team members.

The whole process of adopting Lean philosophy as the building stone of an organization and aligning and sustaining the whole processes and people towards it, is defined as Lean culture. It is very obvious to encounter a Lean failure if an organization tries to imitate the visible Toyota Way. It is very important to understand that the visible Lean tools and practices are just the "Artifacts" which can be related to the tip of the iceberg and adopting these tools may yield some short-term benefits but in the long-run, it won't yield. Therefore, it is important for an organization to assess its culture, understand its strength and weakness, and then adopt Lean principles in their Business Excellence Model.

\section{LEAN AND ORGANIZATIONAL CULTURE}

This section of the literature review will try to explain: Why and how people resist change? What can make people embrace change? What are the enablers of Lean adoption? How is organizational culture related and important for sustaining Lean?

The literature on Lean implementation barriers states "Resistance to change" as a common hindrance for Lean implementation across the service industries. (Cano et al. 2015; Devaki and Jayanthi 2014; R. Jadhav et al. 2014; Salonitis and Tsinopoulos 2016; Shang and Sui Pheng 2014). Some of the reasons for resistance to change are: culture of distrust (when people are uncertain about the change process), Fear of unknown (lack of 
clarity about the change process), personality conflicts (conflicts between the Lean expert and the employees), competing commitments, past negative experiences and violation of personal compacts (personal compacts is the relationship between the employees and the management with regard to the mutual obligations and commitments (Strebel 2018)). People resist change by raising vocal opposition, false commitments, poor attitudes, deliberate failures and negative peer pressure. Although there are ways and means by which people resist change, there are certain enablers that can make people embrace change. These enablers are active and visible leadership by senior and middle management, community-based leadership, employee initiative, providing reliable information, training for senior management, positive and strong relationships between workers, employee empowerment and developing employees as an integral part of the organization(Alkhoraif and McLaughlin 2016; Keyser et al. 2016). It can be seen that these enablers are strongly related to the organizational culture. The type of leadership style, the involvement of people in the processes, developing and empowering people are all directly related to the culture of an organization. Few organizations may be able to take these types of initiatives for adopting Lean and few may find it difficult and complicated to cope up with these needed changes. Thus, it calls for an appropriate change management strategy. To implement a change management strategy, it is important to understand, "what you are" and what you should be". In other words, it is necessary to assess and understand the current organizational culture and should be able to fix a desired organizational culture. The journey from the current state to the desired state should be in incremental steps, analyzing the variations and improvement that take place in every step. There has been a study conducted in Brazil to find out the Ideal Lean Culture (Paro and Gerolamo 2017), which managers can use to benchmark the progress of their own journey. However, the study considered only the desired organizational culture for sustaining Lean.

This study will be focusing on understanding the current organizational culture in the construction sector in the Lean implementation context.

\section{RESEARCH METHODOLOGY}

This research has employed an exploratory study to understand and assess the organizational culture and the impact of its dimensions in Lean adoption. A large Indian construction company was chosen based on its active program in Lean implementation. Competing Values Framework (CVF) has been chosen to analyze the organizational culture for this study. This frameworkutilizesOrganizational Culture Assessment Instrument (OCAI) for collecting the data in the form of a questionnaire survey. Details of CVF and OCAI has been shared in the next section of this paper. The basic steps involved in CVF are:

a. Assessment of the current culture

b. Analysis of the current culture

c. Setting and scoring the desired culture

d. Analysing the desired culture

e. Finding the difference between current vs. desired culture 
But for this study, the desired culture was not assessed and evaluated. The current culture of the organization was focussed. The questionnaire was distributed to 5 members of top management, and 5 members of the middle level. All the employees were asked to score the statements in the scale of 100, for the six different dimensions (Dominant characteristics, Leadership, Organizational glue, management of employees, strategy, Criteria for success) as per the current culture. The score of the first, second, third and fourth statement of each six dimensions was added together to get the total score for Clan, Adhocracy, Market and Hierarchy Culture respectively. After getting the score for each of the six dimensions, the average has been taken for these cultures.

\section{COMPETING VALUES FRAMEWORK (CVF)}

$\mathrm{CVF}$ is one of the most used and validated model for organizational culture assessment. $\mathrm{CVF}$ is a relevant model to understand, how the organization operates and the values that characterize it. As organizational culture is complex, CVF uses two dimensions as shown in Fig 1. One dimension of CVF emphasizes flexibility and stability. The other dimension differentiates an organization's internal focus with an external focus. These dimensions create four quadrants which define the values of an organization (Cameron and Quinn 2006). OCAI assess organizational culture with six key dimensions which are described below:

a. Dominant Characteristics: It defines the level of teamwork, creativity, focus on competition \& goals.

b. Organizational Leadership: It defines leadership style.

c. Management of Employees: It defines the level of participation, consensus etc.

d. Organizational Glue: It defines cohesion between people.

e. Strategic Emphases: It defines employee development, stability, goal setting etc.

f. Criteria for Success: It is defined by how success is evaluated (market share, cost, etc.) 


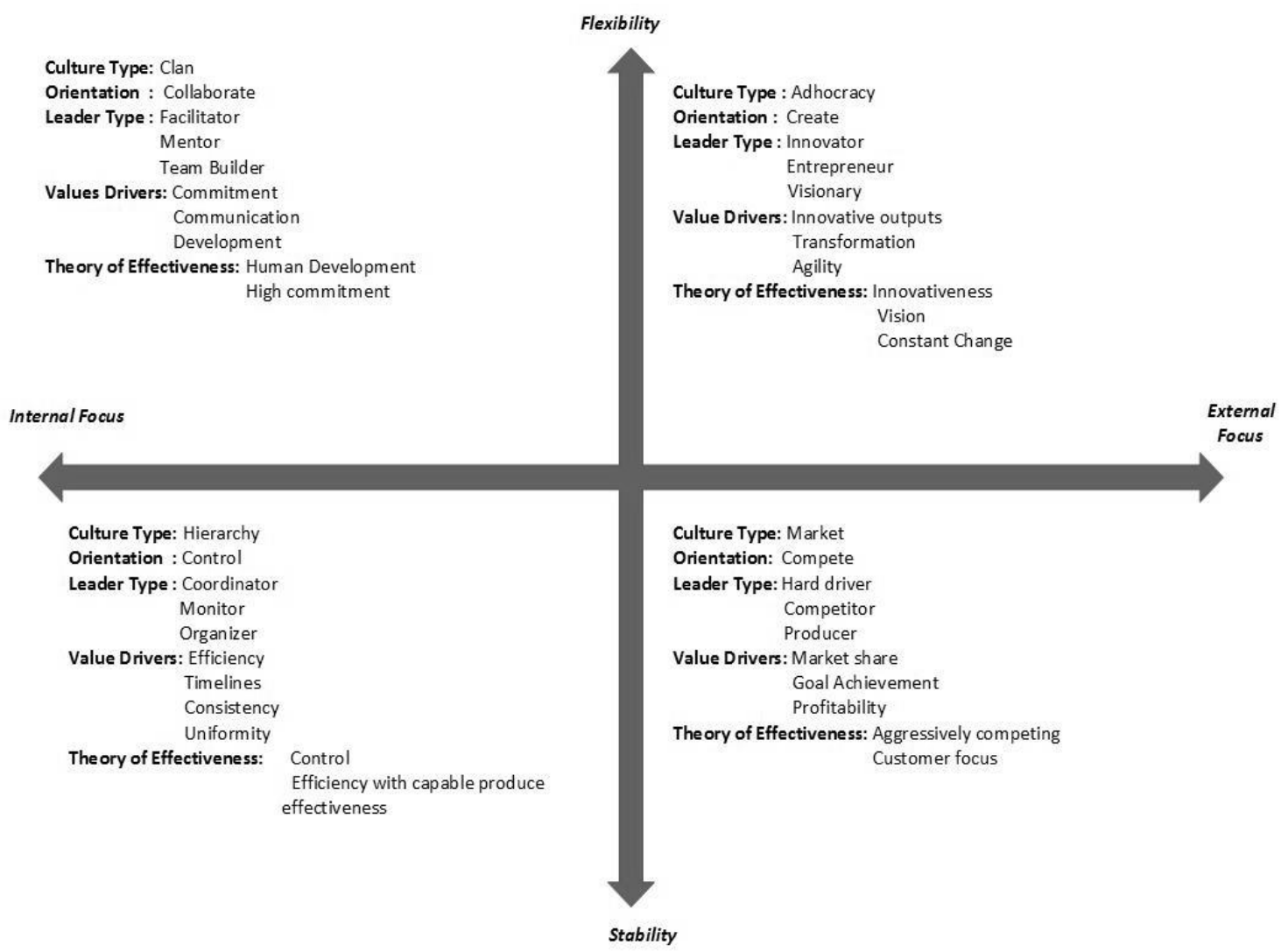

Fig. 1: Competing Values Framework

The scores from the OCAI instrument will help to find out the current organizational culture from the prominent cultures viz. Clan/Adhocracy/Market/Hierarchy culture. The above four organizational cultures are briefly explained below:

a. Clan Culture: This organization has a friendly environment. Leaders are mentors or can be called as facilitators. Groups show loyalty and are more traditional. Employee development and cohesion among the groups are given more priority.

b. Hierarchy Culture: This organization is formal and highly structured. Employee behavior is governed by rules, procedures, and standards. Leaders try to become good coordinators.

c. Adhocracy Culture: This organization is highly dynamic, creative and entrepreneurial. People try to innovate and take risks. Freedom and initiatives are appreciated.

d. Market Culture: This organization is focussed on execution. Employees tend to be competitive $\&$ goal oriented. Success and reputation are of high priority.

\section{FINDINGS}

From the OCAI analysis, the CVF values are found to be: Clan Culture - 25 points, Adhocracy culture - 12 points, Market culture -17 points and Hierarchy culture - 26 points. The resulting CVF model has been shown in Fig. 2. 


\section{Current Culture of the Organization}

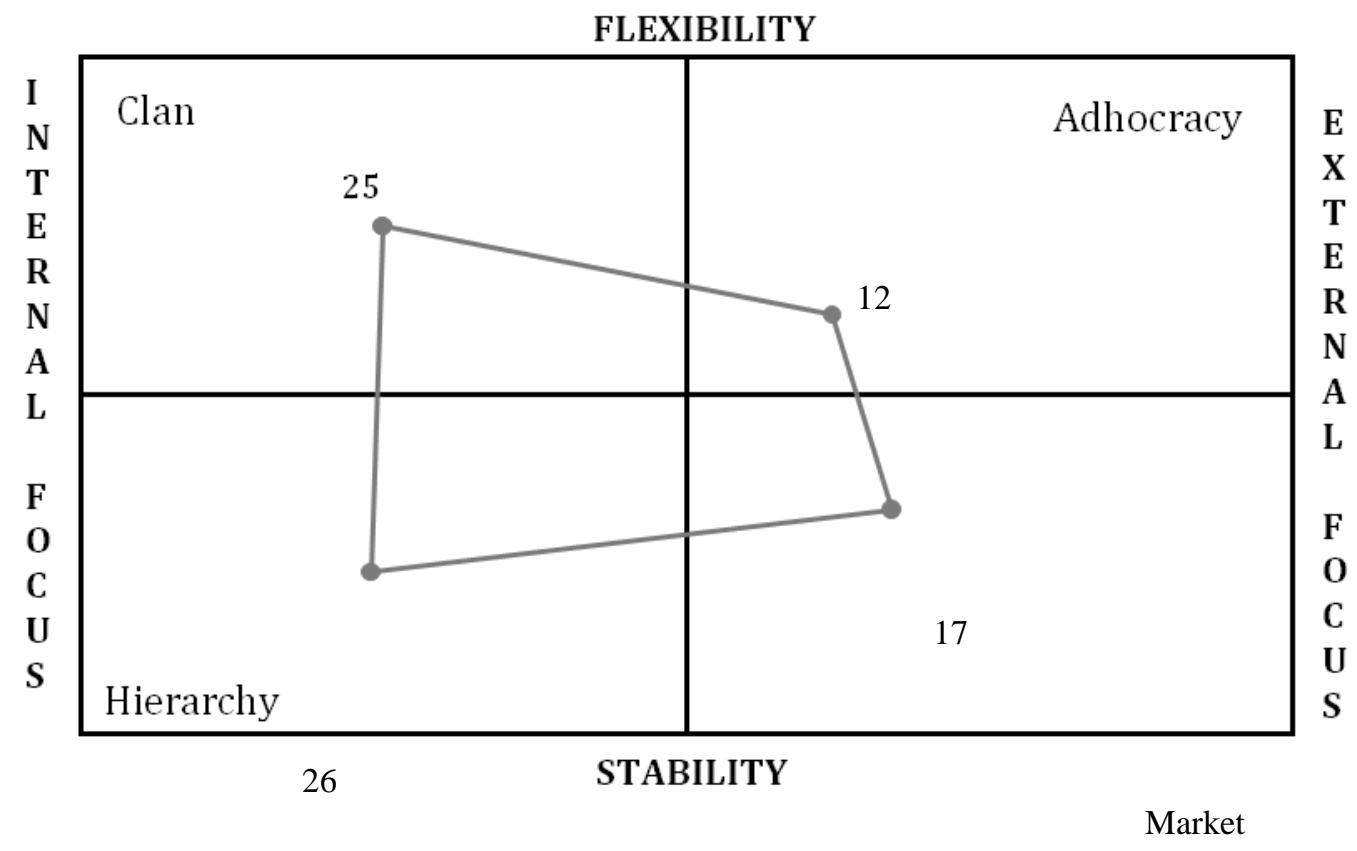

Figure 2: Current culture of the case organization

\section{DISCUSSION}

As mentioned earlier, it is important to align Lean culture with the organizational culture in order to sustain effectiveness of Lean implementations. In a study conducted by Delhi et.al in Lean culture, reported that the behaviour of people changed once they realised that they are not under the direct watch of top management (Delhi et al. 2017). This type of behaviour can be related to fat behaviour as mentioned by Emiliani (Emiliani 1998). A fat behaviour can be related to any behavioural action of a person that adds no value to the processes. e.g.wasteful verbal content, confusion, negativity, ambiguity, deception, inaction etc. It is evident from the observation made by Delhi et.al that there are few behaviours in the employees which does not align with the Lean culture which can be linked to resistance of people to change. From the definition of organizational culture by Schein, it can be inferred that if this type of behaviour continues, it can become the norm of the organization. However, fat behaviour is a threat in sustaining Lean philosophy. In order to have a basic understanding of the dynamics of an organizational culture, its assessment at the current scenario is required.

As already discussed in the earlier section, CVF has been used to assess the organizational culture. The organizational culture dimensions considered in the CVF model are dominant characteristics, organizational leadership, management of employees, organizational glue, strategic emphases and criteria for success. 
As per the results obtained by the survey, it has been observed that the CVF values for hierarchical and clan culture is approximately equal. On further analysis, it is found that the perception and views of employees of different management levels are different. Top management employees view the organizational culture as clan whereas the middle management employees view it as hierarchical. The top management believesthat the organization is more formal and collaborated, and the procedures and standards govern the working of the organization; whereas the employees of middle management level perceive that the organization is more goal oriented and the leaders are demanding.

Further analysis has been done with respect to the six dimensions of the CVF model, in order to understand the impact of these dimensions on the overall organizational culture. The results of detailed investigation are explained below:

Dominant characteristics: Weightage given to the organization for being a controlled and structured place, governed by formal procedures is very high, compared to the weightage given to the characteristics of clan culture. It is clear that this dimension resembles the characteristics of a hierarchical culture.

Organizational leadership: Weightage given for leadership to exemplify mentoring, facilitating or nurturing is almost equal to the weightage given to leadership that coordinates and organizes the smooth running. So, in this case, it is not possible to differentiate if the organization exhibits the characteristics of clan or hierarchical culture.

Management of employees: From the result, it can be clearly stated that the management style in the organization is characterized by team work, consensus and participation which resembles the characteristics of clan culture.

Organizational glue, Strategic emphases, Criteria for Success: The weightages for the characteristics of hierarchical and clan culture for this dimension are approximately equal to the each other. Thus, further investigation is needed to understand the impact of this parameter.

It is not possible to draw any definitive conclusions in this study. The type of organizational culture required for sustaining lean is not simplistic but a complex multidimensional issue. But, the present study helps to understand that there are different perceptions about organizational culture among the employees. It also highlights the need for detailed research in the area to find the implications of various other cultural dimensions apart from the six dimensions of CVF.

\section{SUMMARY \& FURTHER WORK}

This study has adopted an exploratory research methodology to understand the organizational culture in the construction sector with respect to Lean adoption. The study helped to understand that the perception of employees regarding the organizational culture at different management levels varies, which is a potential threat to sustain Lean.

The study is limited to a case with less number of respondents for the survey and interviews. Further detailed investigation has to be done to understand the impact of cultural dimensions on the organizational culture. 


\section{ACKNOWLEDGMENT}

The authors would like to thank Mr. Yeshwanth Sainath, a Post-graduate student at IIT Madras, for helping in data collection and would like to appreciate all the respondents and experts for giving us their valuable time and expertise.

\section{REFERENCES}

Alkhoraif, A., and McLaughlin, P. (2016). "Organizational Culture that Inhibit the Lean Implementation." (July), 39-58.

Cameron, K. s., and Quinn, R. E. (2006). Diagnosing and Changing Organizational Culture.The Jossey-Bass Business \& Management Series.

Cano, S., Delgado, J., Botero, L., and Rubiano, O. (2015). "Barriers and Success Factors in Lean Construction Implementation -Survey in Pilot Context." (100), 631-641.

Delhi, V. S. K., N, R., Mahalingam, A., and Varghese, K. (2017). "Initial Euphoria to Sustained Change - Mainstreaming Lean Culture.” II(July), 267-274.

Denison, D. R., and Neale, W. S. (1999). "Denison Organizational Culture Survey: Facilitator Guide." Denison Consulting, LLC, 104.

Devaki, M. P., and Jayanthi, R. (2014). "Barriers to Implementation of Lean Principles in." International Journal of Engineering Research \& Technology, 3(5), 1189-1192.

Emiliani, M. L. (1998). "Lean behaviors.” Management Decision, 36(9), 615-631.

Hofstede, G. (2011). "Dimensionalizing Cultures: The Hofstede Model in Context." Online Readings in Psychology and Culture, 2(1), 1-26.

Keyser, R. S., Sawhney, R. S., and Marella, L. (2016). "A management framework for understanding change in a lean environment." Tékhne, Instituto Politécnico do Cávado e do Ave (IPCA), 14(1), 31-44.

Matthias Holweg. (2007). "The genealogy of lean production." Journal of Operations Management, 25, 420-437.

Paro, P. E. P., and Gerolamo, M. C. (2017). "Organizational culture for lean programs." Journal of Organizational Change Management, 30(4), 584-598.

R. Jadhav, J., S. Mantha, S., and B. Rane, S. (2014). "Exploring barriers in lean implementation.” International Journal of Lean Six Sigma, 5(2), 122-148.

Salonitis, K., and Tsinopoulos, C. (2016). "Drivers and Barriers of Lean Implementation in the Greek Manufacturing Sector." Procedia CIRP, The Author(s), 57(December), 189-194.

Schein, E. H. (2004). “Organizational Culture and Leadership.” Leadership, 7, 437.

Shang, G., and Sui Pheng, L. (2014). "Barriers to lean implementation in the construction industry in China." Journal of Technology Management in China, 9(2), 155-173.

Strebel, P. (2018). "Why do Employees Resist Change?" Harvard Business Review, (May-June 1996), 1-13.

Zamanabadi, K. I. (2017). "Hofstede $\hat{a} €^{\mathrm{TM}}$ S Cultural Dimensions and National Innovation Level." 3(1), 45-49. 